Азиатско-Тихоокеанский регион: экономика, политика, право. 2021. Т. 24, № 4. С. 132-144. Pacific Rim: Economics, Politics, Law. 2021. V. 24, No 4. P. 132-144.

\title{
ПРАВО
}

Научная статья

УДК 341.123(094.2):316.647.5

https://doi.org/10.24866/1813-3274/2021-4/132-144

\section{ПОНЯТИЕ "TOLERANCE" В ДОКУМЕНТАХ ООН: ЛИНГВО-ПРАВОВОЕ ОБОСНОВАНИЕ НЕОБХОДИМОСТИ ВНЕСЕНИЯ ИЗМЕНЕНИЙ}

\author{
Дмитрий Александрович Кириллов ${ }^{1}$, Екатерина Григорьевна Сеченова ${ }^{2}$ \\ 1,2 Тюменский государственный университет, 625003, Россия, Тюмень, \\ ул. Володарского, 6 \\ ${ }^{1}$ kdakda@yandex.ru, https://orcid.org/0000-0002-1550-1962, Author ID: 715562 \\ (e-library) \\ 2 e.g.sechenova@utmn.ru, https://orcid.org/0000-0001-5500-8972, Author ID \\ 520638 (e-library)
}

Аннотация. Необходимость исследования данной проблемы связана с отдельными противоречиями в документах Организации Объединённых Наций $(\mathrm{OOH})$ и необходимостью их устранения. Целью статьи является обоснование целесообразности внесения в документы ООН изменений в связи с некорректным использованием в них понятия "tolerance" и его аналогов, в том числе в русскоязычных версиях. В основной части исследования авторы на основе выполненного ими сравнительного анализа содержания Резолюций Генеральной ассамблеи ООН, в части использования понятия "tolerance", приходят к обнаружению ими в документах ООН двух групп противоречий, которые требуют разрешения. Авторы подробно рассматривают эти две группы противоречий, отмечая их характерные признаки. Общечеловеческие права приоритетны по отношению к правам людей, определяемым их расовой, религиозной, этнической принадлежностью, а также иными имманентными признаками. Обострившиеся на фоне пандемии COVID-19 социальные противоречия привели к ряду конфликтов на почве вражды к носителям «инаковости». События 2020 г. показали, что во взаимоотношения между людьми с различающимися имманентными признаками настоятельно необходимо внедрять «гар-

(C) Кириллов Д. А., Сеченова Е. Г., 2021 
монию в многообразии». Обеспечить последнюю призван международный политико-правовой институт, обозначенный на рабочих языках $\mathrm{OOH}$ терминами "tolerance" и "la tolérance". Между тем, в настоящее время существует множество обстоятельств, препятствующих реализации идеи "tolerance" ("la tolérance"). Важнейшим из них представляется отсутствие в официальных документах $\mathrm{OOH}$ чёткой позиции относительно содержания идеи. В ходе анализа этих документов выявлены противоречия при использовании понятия "tolerance" ("la tolérance") и его аналогов, в том числе в русскоязычных версиях. Так, понятие "tolerance" ("la tolérance") до сих пор используется в документах $\mathrm{OOH} \mathrm{в} \mathrm{значении,} \mathrm{содержащемся} \mathrm{в}$ Уставе ООН. Между тем, в 1995 г. ЮНЕСКО по поручению ООН была принята Декларация принципов "tolerance" ("la tolérance"), в которой детально раскрыт принцип "tolerance" ("la tolérance") как оптимальный принцип взаимоотношений между людьми с различающимися имманентными признаками. ООН в своих документах игнорирует содержание Декларации. Тем самым ООН не только не использует потенциал идеи "tolerance" ("la tolérance"), но и даёт серьёзный повод противникам идеи говорить о её бесполезности. Кроме того, в документах $\mathrm{OOH}$ на русском языке в качестве аналога "tolerance" ("la tolérance") используются взаимоисключающие понятия «толерантность» и «терпимость». Это затрудняет понимание идеи "tolerance" ("la tolérance") людьми, которым адресованы русскоязычные версии документов ООН. Цель статьи - обосновать необходимость устранения вышеуказанных противоречий в документах ООН. Предложены меры по внесению изменений, связанных с понятием "tolerance", как в документы ООН в целом, так и в их русскоязычные версии. В статье обосновано, что без внесения изменений в документы эффективность продвижения идеи "tolerance" и дальше продолжит снижаться. Также в статье предложены меры по внесению изменений, связанных с понятием "tolerance", как в документы $\mathrm{OOH}$ в целом, так и в их русскоязычные версии. Основной вывод, сделанный авторами, заключается в том, что без внесения в документы ООН изменений эффективность продвижения идеи "tolerance" и дальше продолжит снижаться.

Ключевые слова: "tolerance", базовое значение, оптимальный принцип взаимоотношений, имманентные признаки, декларация принципов терпимости, la tolérance, терпимость, толерантность, декларация ЮНЕСКО, гармония в многообразии, инаковость, рабочие языки ООН, русскоязычная версия, причины несоответствия, многолетние шаблоны, религиозное превосходство, Резолюция 36/55, Резолюция 48/126, Резолюция 69/312, Резолюция 73/128, Резолюция 75/237.

Для ичитирования: Кириллов Д. А., Сеченова Е. Г. Понятие "tolerance" в документах ООН: лингво-правовое обоснование необходимости внесения изменений // Азиатско-Тихоокеанский регион: экономика, политика, право. 2021. Т. 24, № 4. C. 132-144. https://doi.org/10.24866/1813-3274/2021-4/ 132-144. 


\title{
LAW
}

Original article

\section{THE CONCEPT OF "TOLERANCE" IN UN DOCUMENTS: LINGUISTIC AND LEGAL ARGUMENTS TO SUPPORT MODIFICATINOS}

\author{
Dmitry Alexandrovich Kirillov ${ }^{1}$, Ekaterina Grigorievna Sechenova ${ }^{2}$ \\ 1,2 Tyumen State University, 6, Volodarskogo st., Tyumen, Russia, 625003 \\ ${ }^{1}$ kdakda@yandex.ru; ORCID https://orcid.org/0000-0002-1550-1962 \\ 2 e.g.sechenova@utmn.ru; ORCID https://orcid.org/0000-0001-5500-8972
}

Abstract. The need to study this problem is associated with individual contradictions in the United Nations (UN) documents and the need to eliminate them. The purpose of the article is to substantiate the advisability of making changes to UN documents due to the incorrect use of the concept of "tolerance" and its analogues, including in Russian versions. In the main part of the study, the authors, on the basis of their comparative analysis of the content of the UN General Assembly Resolutions, in terms of the use of the concept of "tolerance", come to the discovery of two groups of contradictions in UN documents that require resolution. The authors examine these two groups of contradictions in detail, noting their characteristic features. Universal human rights take priority over the rights of people determined by their racial, religious, ethnic affiliation, as well as other immanent features. The social contradictions that have worsened against the background of the COVID-19 pandemic have led to a number of conflicts based on hostility towards carriers of "otherness". The events of 2020 have shown that it is imperative to introduce "harmony in diversity" into the relationships between people with different immanent features. The international political and legal institute, designated in the working languages of the United Nations by the terms "tolerance" and "la tolerance", is designed to provide this harmony. Meanwhile, at present there are many circumstances that prevent the implementation of the idea of "tolerance" ("la tolérance"). The most important of them is the lack of a clear position in official UN documents regarding the content of the idea. The analysis of UN documents, including the Russian-language versions, revealed contradictions in the use of the concept of "tolerance" ("la tolérance") and its analogues. Thus, the concept of "tolerance" ("la tolerance") is still used in UN documents in the meaning contained in the UN Charter. Meanwhile, in 1995, UNESCO, on behalf of the UN, adopted the Declaration of Principles of "tolerance" ("la tolérance"), in which the principle of "tolerance" ("la tolérance") is disclosed in detail as an optimal principle of relationships between people with different immanent features. The UN ignores the con- 
tent of the Declaration in its documents. Thus, the UN not only does not use the potential of the idea of "tolerance" ("la tolerance"), but also gives a serious reason to the opponents of the idea to talk about its uselessness. In addition, in the UN documents in Russian as an analogue of "tolerance" ("la tolérance") the mutually exclusive concepts of "tolerantnost"" i "terpimost"' are used. The purpose of the article is to give reasons for the need to eliminate the above contradictions in UN documents. The article proves that the effectiveness of promoting the idea of tolerance will continue to decline without the required changes to UN documents. It proposes measures to introduce changes related to the concept of "tolerance," both in UN documents and in their Russian-language versions. The main conclusion made by the authors is that without making changes to the UN documents, the effectiveness of promoting the idea of "tolerance" will continue to decline further.

Keywords: tolerance, basic meaning, optimal principle of relationships, immanent features, declaration of principles of tolerance, la tolérance, terpimost', tolerantnost', UNESCO declaration, harmony in diversity, otherness, UN working languages, Russian version, reasons for inconsistency, long-years patterns, religious superiority, Resolution 36/55, Resolution 48/126, Resolution 69/312, Resolution 73/128, Resolution 75/237.

For citing: Kirillov D. A., Sechenova E. G. The concept of "tolerance" in UN documents: linguistic and legal arguments to support modificatinos // Pacific RIM: Economics, Politics, Law. 2021. V. 24, No 4. P. 132-144. https://doi.org/10.24866/18133274/2021-4/ 132-144.

\section{Необходимость исследования данной проблемы}

Из логики цивилизованного миропонимания следует, что по отношению к правам человека, определяемым признаками религиозной, расовой, гендерной, хронотипной, политической, языковой, национальной, территориальной и иной разделяющей людей на группы принадлежности (далее - имманентные признаки), общечеловеческие права приоритетны. Именно поэтому во взаимоотношениях между людьми с различающимися имманентными признаками важна гармония, обеспечить которую призван международный политико-правовой институт, обозначенный на рабочих языках [7] Организации объединённых наций (далее - OOH) терминами "tolerance" и "la tolérance", а также их иноязычными аналогами. Эти же термины используются и для обозначения оптимального с точки зрения $\mathrm{OOH}$ принципа взаимоотношений людей с различающимися имманентными признаками.

Обострившиеся на фоне пандемии COVID-19 социальные противоречия высветили низкую эффективность функционирования института "tolerance". Среди причин этого, на наш взгляд, - многолетняя системная противоречивость документов $\mathrm{OOH}$, содержащих термин "tolerance" и его иноязычные аналоги. Данное обстоятельство, по меньшей мере, препятствует «мягко-правовому» продвижению ООН идеи "tolerance" и 
нейтрализует предпосылки к институционализации основного смысла идеи - приоритета общечеловеческих ценностей. В связи с этим, целью статьи является обоснование целесообразности внесения в документы ООН изменений в связи с некорректным использованием в них понятия "tolerance" и его аналогов.

\section{Основная часть исследования}

В русском языке единого аналога термину "tolerance" нет, в качестве таковых используются два термина - «терпимость» и толерантность». Понятийное наполнение данных терминов разнится. Потому вместо них для удобства, при отсутствии оговорки, в ходе воспроизведения документов ООН на русском языке будет использоваться англоязычный термин "tolerance".

Сравнительный анализ содержания Резолюций Генеральной ассамблеи ООН (далее - ГА ООН) в части использования понятия "tolerance" привёл к обнаружению нами в документах ООН двух групп противоречий, которые требуют разрешения. Заключаются противоречия в следующем.

Первая группа противоречий в документах $\mathrm{OOH} \mathrm{касается} \mathrm{их} \mathrm{содержания} \mathrm{на}$ всех шести официальных языках ООН. Далее при рассмотрении противоречий этой группы всё сказанное о понятии "tolerance" в русскоязычных версиях документов относимо и к его аналогам в документах на других языках.

В документах $\mathrm{OOH}$ по «частным» темам значение понятия "tolerance" не согласуется с его значением в документах, где дана характеристика и раскрыто содержание данного понятия как оптимального принципа взаимоотношений между людьми и группами людей с различающимися имманентными признаками (далее «оптимальный принцип взаимоотношений»).

Рассмотрим сложившуюся ситуацию и типичный пример.

"Tolerance" как понятие, отражающее обращённое к мировому сообществу мнение ООН об «оптимальном принципе взаимоотношений», включено в Устав ООН от 26.06.1945 (далее - «Устав ООН»), где преамбуле, в частности, говорится: «Мы, народы ООН, преисполненные решимости ... проявлять "tolerance" ...» [12].

В порядке реализации предложения ГА ООН из тематической Резолюции ГА ООН № 48/126 от 14.02.1994 (далее - «Резолюция 48/126») [3] 16 ноября 1995 г. ЮНЕСКО приняла раскрывающую "tolerance" как оптимальный принцип взаимоотношений «Декларацию принципов "tolerance" (далее - «Декларация»). В пункте 1.1 русскоязычной версии «Декларации», в частности, указывается, что "tolerance" «...означает уважение, принятие и правильное понимание богатого многообразия культур нашего мира, наших форм самовыражения и способов проявлений человеческой индивидуальности...» [5]. Значение понятия "tolerance" в «Декларации», принятой во исполнение «Резолюции 48/126», можно назвать базовым (далее - «базовое значение»). Для текущего контекста заметим, что в «базовом значении» по- 
Кириллов Д. А., Сеченова Е. Г. Понятие "tolerance" в документах ООН:

лингво-правовое обоснование необходимости внесения изменений

нятие «уважение» включено в качестве части в «собирательное» понятие "tolerance".

В документах же «частной» тематики подход иной. Так, в Резолюции ГА ООН от 06.07.2015 № 69/312 (далее - «Резолюция 69/312»), которая содержит текст «...поощряя "tolerance", уважение, диалог и сотрудничество...» [1], значение понятия "tolerance" не соответствует «базовому». Если предположить обратное, то однородность членов предложения "tolerance" и «уважение» в приведённом фрагменте исключается. В подтверждение произведём замену "tolerance" в тексте фрагмента «Резолюции 69/312» на «базовое значение» с последующей небольшой перестановкой членов предложения. В результате в «Резолюции 69/312» получаем преобразованный текст: «...поощряя уважение, уважение, принятие, правильное понимание, диалог и сотрудничество...». Абсурдность «смоделированного» результата фразеологически очевидна. Несоответствие «базового значения» и текущего значения понятия "tolerance" налицо.

Напомним, что рассмотренный пример мы назвали типичным; нами обнаружено более трёхсот официальных документов ООН, принятых после принятия «Декларации», в которых текущее значение понятия "tolerance" не соответствует «базовому значению». Говоря о гипотетически возможных причинах такого несоответствия, их следует, на наш взгляд, объединить в две взаимоисключающие группы. Для первой из них подразумевается, а для второй исключается распространение «базового значения» на все документы ООН.

В основе первой группы гипотетических причин лежит человеческий фактор. Среди них - системные стереотипность мышления, недомыслие, небрежность, поспешность, недограмотность и т.П. составителей документов ООН в сочетании с возможным безразличием к содержанию документов со стороны принимающих их должностных лиц. В пользу наличия таких причин указывает, к примеру, тот факт, что многолетние шаблоны использования понятия "tolerance" в документах ООН, принятых до 1995 г., перешли в документы, принятые после 1995 г. Показательна Резолюция ГА ООН № 36/55 от 25.11.1981 (далее - «Резолюция 36/55»), где, в частности, сказано: «...содействовать пониманию, терпимости и уважению...» ("...to promote understanding, tolerance and respect...") [4].

В основе второй группы гипотетических причин лежит документарноиерархический фактор. Так, если исходить из названия «Резолюции 48/126», содержащей адресованное ЮНЕСКО предложение о разработке «Декларации», то резолюция формально касается лишь проведения в 1995 г. «Года "tolerance", а «Декларация» во внимание не принимается ввиду её невысокого статуса, поскольку документом ООН она не является. По этой логике одна из причин несоответствия текущих и «базового» значений состоит в использовании понятия в смысле, соответствующем «Уставу ООН», где в порядке конкретизации "tolerance" указано 
«...жить вместе, в мире друг с другом, как добрые соседи». При подобном подходе дополнение каждого документа ООН сверх «уставного значения» понятия "tolerance" такими элементами смыслового ряда "tolerance", как уважение, принятие, признание, правильное понимание и подобными выглядит абсолютно логичным. Так же, как и в случае с приведённым выше фрагментов «Резолюции 36/55».

По нашему мнению, причины второй группы ближе к объяснению сложившегося положения вещей. Так, даже предположение о возможности существования причин первой группы представляется малоуместным, тогда как игнорирование «базового значения» согласуется с формально-юридическим подходом, хоть и с некоторым, на наш взгляд, уклоном в легизм.

Между тем, независимо от причин, значение понятия "tolerance" в текущих документах ООН существенно обедняет позитивный социальный потенциал, который мог бы быть гораздо выше при отсылочно-бланкетной «привязке» понятия к развёрнутому описанию «оптимального принципа взаимоотношений» из «Декларации». Также здесь усматриваются и предпосылки к внешнему восприятию позиции ООН об «оптимальном принципе взаимоотношений» как о не заслуживающей внимания информации. Кроме того, очевиден ущерб и самой идее "tolerance", как, якобы, исходящей от проявляющего явную непоследовательность субъекта $(\mathrm{OOH})$, что даёт возможность противникам идеи пропагандировать другие, в том числе основанные на напряжённости принципы взаимоотношений между носителями различных имманентных признаков. И, наконец, можно говорить о крайне низком уровне информационного сопровождения идеи "tolerance", ограниченном в документах ООН смысловой «отсылкой» лишь к Уставу ООН. Этот уровень гораздо ниже возможного, будь организация продвижения идей «Декларации» надлежащей. Так, например, в упомянутой выше «Резолюции 69/312» среди базовых для Альянса цивилизаций документов поименованы лишь Устав ООН и Всеобщая декларация прав человека, но не указана «Декларация» - документ, где "tolerance" как оптимальный принцип взаимоотношений между всеми людьми и их группами раскрыт во всей полноте. Значение же понятия "tolerance" в связи со ссылкой лишь на Устав ООН имеет ущербное с позиций современного знания значение.

В целом можно сделать вывод о том, что сегодня со стороны ООН не обеспечена информационная основа для надлежащей институционализации "tolerance" как оптимального принципа взаимоотношений, раскрытого в «Декларации», что не могло не повлечь издержек при фактической институционализации. Данное негативное обстоятельство в полной мере проявилось в 2020 г., в том числе и в ряде стран «первого мира», в виде «прорывной» масштабности конфликтов между людьми на основе различий по имманентным признакам.

Ситуация не меняется и после событий 2020 года. Так, в «чрезвычайной» Резолюции ГА ООН № 75/237 от 31.12.2020 (далее - «Резолюция 75/237»), отражающей проблематику всколыхнувших весь мир событий, содержится формулировка: 
«...необходимость содействия "tolerance", инклюзивности и уважению многообразия...» ("...the need to promote tolerance, inclusion and respect for diversity...") [2], в очередной раз словно не учитывающая самого существования «Декларации».

Необходимым условием исправления ситуации видится скорейшее отражение в документах $\mathrm{OOH}$ идеи "tolerance" в «базовом значении». Для этого было бы целесообразным во все документы ООН общегуманитарной направленности, принятые после 1995 г., внести дополнения в виде отсылки к «Декларации» как к элементу системы документов ООН об основах цивилизованного мироустройства. Одновременно значение понятия "tolerance" в документах этого периода следует привести в соответствие с «базовым значением».

Учитывая также, что ЮНЕСКО по формальному статусу всё-таки ниже ООН, для повышения уровня рейтинговой значимости «оптимального принципа взаимоотношений», возможно, стоило бы по итогам событий 2020 г. принять специальную резолюцию ГА ООН об утверждении «Всеобщей декларации толерантности», приняв за основу содержание «Декларации».

Вторая группа противоречий в документах $\mathrm{OOH}$ в части использования понятия "tolerance" касается русскоязычных версий документов. В качестве аналогов понятию "tolerance" в них используются понятия «терпимость» и «толерантность», значения которых различаются. Подобная рассогласованность выявилась при анализе Резолюции ГА ООН от 12.12.2018 № 73/128 «Просвещение и религиозная толерантность» (далее - «Резолюция 73/128») [8].

В течение семидесяти трёх лет существования $\mathrm{OOH}$ термину "tolerance" в англоязычных версиях документов ООН и «Декларации» соответствовал термин «терпимость» в русскоязычных версиях. В тексте же «Резолюции 73/128» в качестве аналога термину "tolerance" впервые в истории ООН в версии на русском языке использован термин «толерантность». Из текста документа следует, что, согласно позиции ГА ООН, толерантность как понятийная единица касается взаимоотношений людей, различающихся не только по признакам, относимым к религиозной сфере, но и по всем иным имманентным признакам.

Заметим, что в документах ООН, принятых после «Резолюции 73/128», несколько раз на протяжении почти двух лет англоязычному термину "tolerance" coответствовал исключительно русскоязычный термин «терпимость». И только ближе к завершению 2020 г., как, к примеру, в «Резолюции 75/237» [2], в русскоязычных документах $\mathrm{OOH} \mathrm{вновь} \mathrm{стал} \mathrm{использоваться} \mathrm{термин} \mathrm{«толерантность».} \mathrm{Между}$ тем, несмотря на «терминологическую непоследовательность», понятие "tolerance" из документов $\mathrm{OOH}$ на английском языке сегодня одновременно сопрягается с двумя разными понятиями на русском языке. Первое понятие - «терпимость», которое поименовано и содержание которого раскрыто в русскоязычной версии «Декларации». Второе - «толерантность»; содержание понятия в русскоязычном сег- 
менте документов ООН не раскрыто, но понятие распространено, в частности, «Резолюцией 73/128» и «Резолюцией 75/237» на взаимоотношения всех субъектов со всевозможными различающимися имманентными признаками.

В связи с этим, во всём сообществе пользователей русскоязычных версий документов ООН возникает вопрос, какое из понятий - терпимость или толерантность - в большей степени подходит для обозначения «оптимального принципа взаимоотношений». Для ответа на вопрос было бы корректно, на наш взгляд, исходить из следующего. Безотносительно к русскоязычному аналогу "tolerance" «оптимальный принцип взаимоотношений» в содержательном аспекте детально раскрыт в «Декларации». В связи с этим, мы сочли уместным использовать приёмы терминологического анализа и сравнить между собой (а также с содержанием «Декларации») некоторые элементы понятий «терпимость» и «толерантность». То из двух понятий, которое будет в большей степени соответствовать содержанию «Декларации», и следует, на наш взгляд, считать адекватным русскоязычным аналогом "tolerance".

В российской исследовательской среде существует три группы позиций о соотношении терпимости и толерантности - совпадение, включение и различие. Так, например, Е. Н. Яркова [13, с. 29] полагает, что понятия «терпимость» и «толерантность» совпадают по смыслу. И. А. Стернин, указывая, что «...толерантность терпимость к людям иной веры, уважение к чужим ... убеждениям...» [11], фактически рассматривает толерантность как составное понятие, которое включает в себя терпимость в качестве одной из частей. А. Рылова разграничивает терпимость и толерантность, указывая, в частности, на наличие в терпимости «...непротивления неприятным или неблагоприятным факторам... Толерантность же ... заключается в одобрении, поддержке разнообразия мира и права на различие...» [9].

При сравнении религиозной терпимости и религиозной толерантности выявлено, что религиозная терпимость не только отличается от религиозной толерантности по ряду параметров, но и несёт черты религиозного превосходства. Признание же терпимости в вопросах веры принципом межрелигиозных отношений имеет, по нашему мнению, черты запрещённой Конституцией пропаганды религиозного превосходства [6].

Полагаем возможным экстраполировать вывод, полученный при анализе явлений в религиозной сфере, на взаимоотношения носителей всех имманентных признаков. Исходя из этого, в основе терпимости лежит осознание собственного превосходства перед носителями отличающихся имманентных признаков. Превосходство может проявляться в разных чувственных формах - от схожих с враждой до граничащих с безразличием. Причём, последнее уже является «негативным видом толерантности» $[10$, c. 84]. В порядке снижения уровня возможной агрессии эти свойственные превосходству формы можно, на наш взгляд, расположить примерно в такой последователь- 
ности: «неприязнь - брезгливость - неуважение - снисхождение - великодушие». Во всех них в основе терпимости лежит чувство превосходства, которое не согласуется с содержанием «Декларации». Кроме того, как известно, для России и российских постимперских территорий термин «терпимость» несёт черты сомнительной коннотации, коренящейся в смысле понятия «веротерпимость». Последняя подразумевала разделение всех вероучений на «главное» вероучение и прочие.

Также заметим, что, распространив всё сказанное о "tolerance" при характеристике первой группы противоречий на его аналог «терпимость», нужно отметить системное несоответствие «базового» и текущих значений понятия «терпимость»в документах ООН на русском языке, принятых после 1995 г. Тем самым, значение понятия «терпимость» в текущих документах ООН к «базовому значению» отношения не имеет, а потому в восприятии адресатов документов сопрягается с «традиционным» смыслом, в том числе, с чувством превосходства «терпящего» лица над носителями отличающихся имманентных признаков. То же самое можно сказать и о российских нормативных правовых актах, где понятие «терпимость» также используется в значении, отличном от «базового».

Таким образом, из двух русскоязычных аналогов понятия "tolerance" содержанию «Декларации» соответствует понятие «толерантность». Термин «терпимость» не следует сопрягать с термином "tolerance", поскольку в основе терпимости лежит чувство собственного превосходства субъекта, исключающее отношение к носителю «инаковости» как к равному и его уважение. Поэтому представляется обоснованной замена в русскоязычных версиях всех документов ООН термина «терпимость» на термин «толерантность».

\section{Выводы}

Обобщая, отметим, что в ходе изучения официальных документов ООН, содержащих понятие "tolerance", нами были выявлены противоречия, которые, по нашему мнению, требуют скорейшего устранения. Без этого эффективность функционирования международного политико-правового института "tolerance" будет оставаться низкой, а идею толерантности мировое сообщество перестанет воспринимать как значимую. В отражённом в настоящей статье сегменте нашего исследования ставилась цель - обосновать целесообразность изменения документов ООН в части использования понятия "tolerance" и аналогов. Статья содержит такое обоснование, а также ещё некоторые предложения, которые приведены в основной её части. Так, в частности, во-первых, целесообразно отразить в документах ООН идею "tolerance" в «базовом значении», раскрытом в «Декларации». Для этого в документы ООН общегуманитарной направленности, принятые после 1995 г., следует внести дополнения в виде отсылки к «Декларации» как к базовому элементу системы документов ООН об основах цивилизованного мироустройства. Во-вторых, 
значение понятия "tolerance" в документах ООН этого периода логично привести в соответствие с «Декларацией». В-третьих, для повышения уровня рейтинговой значимости идеи "tolerance", раскрытой в документе ЮНЕСКО, уместно принятие резолюции ГА ООН об утверждении «Всеобщей декларации толерантности», приняв за основу содержание «Декларации». В-четвёртых, для преодоления терминологической рассогласованности следует заменить в русскоязычных версиях всех документов ООН либо термин «терпимость» на термин «толерантность», либо наоборот. Первый вариант предпочтителен с позиций не только исторической коннотации и лингво-правового анализа, но и здравого смысла.

\section{Список источников}

1. Альянс цивилизаций Организации Объединенных Наций. Резолюция ГА OОН. 06 июля 2015 г. № 69/312. - URL: https://undocs.org/ru/A/RES/69/312 (дата обращения: 08.08.2021).

2. Глобальный призыв к конкретным мерам, направленным на ликвидацию расизма, расовой дискриминации, ксенофобии и связанной с ними нетерпимости и всеобъемлющее осуществление и принятие последующих мер по выполнению Дурбанской декларации и Программы действий. Резолюция ГА ООН. 31 декабря 2020 г. № 75/237. - URL: https://undocs.org/ru/A/RES/75/237 (дата обращения: 08.08.2021).

3. Год ООН, посвященный терпимости. Резолюция Генеральной Ассамблеи OОН. 14 февраля 1994. № 48/126. - URL: https://undocs.org/ru/A/RES/48/126 (дата обращения: 08.08.2021).

4. Декларация о ликвидации всех форм нетерпимости и дискриминации на основе религии или убеждений: Резолюция 36/55 ГА от 25 ноября 1981 г. - URL: https://undocs.org/ru/A/RES/36/55 (дата обращения: 08.08.2021).

5. Декларация принципов терпимости. Резолюция 5.61 Генеральной конференции ЮНЕСКО. 16 ноября 1995 г. - URL: https://www.un.org/ru/docu ments/decl_conv/declarations/toleranc.shtml (дата обращения: 08.08.2021).

6. Кириллов, Д. А. О рассогласованности в регулировании религиозной толерантности Конституцией России и национальным законодательством о свободе совести / Д. А. Кириллов, Е. Г. Сеченова // Вестник ТюмГУ. Социальноэкономические и правовые исследования. - 2019. - № 1. - С. 74-91.

7. Правила о языках. Резолюция Генеральной Ассамблеи ООН. 01 февраля 1946 г. № 1/2. - URL: https://undocs.org/ru/A/RES/2\%28I\%29 (дата обращения: 08.08.2021).

8. Просвещение и религиозная толерантность. Резолюция Генеральной Ассамблеи ООН. 12 декабря 2018 г. № 73/128. - URL: https://undocs. org/ru/A/RES/73/128 (дата обращения: 08.08.2021). 
9. Рылова, А. Термин «толерантность» / «терпимость». Досье // ТАСС. 16.11.2015. - URL: https://tass.ru/info/2441674 (дата обращения: 08.08.2021).

10. Симаворян, А. Религиозная толерантность в современном обществе / А. Симаворян, В. Овян // 21-й ВЕК. - 2013. - № 1 (26). - С. 82-90.

11. Стернин, И. А. Толерантность и терпимость. 18.10.2014. - URL: http://sterninia.ru/index.php/izbrannye-publikatsii/item/188-tolerantnost-i-terpimost (дата обращения: 08.08.2021).

12. Устав ООН. - URL: https://www.un.org/en/sections/un-charter/preamble/in dex.html (дата обращения: 08.08.2021).

13. Яркова, Е. Н. Миграция: типология этнокультурной политики // Вестник Тюменского государственного университета. Социально-экономические и правовые исследования. - 2017. - № 2. - С. 25-35.

\section{Информация об авторах}

Д.А. Кириллов - кандидат юридических наук, доцент, доцент кафедры административного и финансового права ФГАОУ ВО «Тюменский государственный университет».

Е. Г. Сеченова - кандидат филологических наук, проректор по международным связям ФГАОУ ВО «Тюменский государственный университет».

\section{References}

1. United Nations Alliance of Civilizations. UN GA Resolution. July 06, 2015. No. 69/312. Available at: https://undocs.org/en/A/RES/69/312 (accessed 08 August 2021).

2. A global call for concrete action for the elimination of racism, racial discrimination, xenophobia and related intolerance and the comprehensive implementation of and follow-up to the Durban Declaration and Programme of Action. UN GA Resolution. December 31, 2020 No. 75/237. Available at: https://undocs.org/en/A/RES/75/237 (accessed 08 August 2021).

3. United Nations Year for Tolerance. UN GA Resolution. February 14, 1994. No. 48/126. Available at: https://undocs.org/en/A/RES/48/126 (accessed 08 August 2021).

4. Declaration on the elimination of all forms of intolerance and of discrimination based on religion or belief. UN GA Resolution. November 25, 1981. No. 36/55. Available at: https://undocs.org/en/A/RES/36/55 (accessed 08 August 2021).

5. Declaration of principles of tolerance. Approved by resolution 5.61 of the UNESCO General Conference of November 16, 1995. Available at: https://unesdoc.unesco.org/ark:/48223/pf0000151830 (accessed 08 August 2021). 
6. Kirillov D.A., Sechenova E.G. O rassoglasovannosti $v$ regulirovanii religioznoi tolerantnosti Konstitutsiei Rossii i natsional'nym zakonodatel'stvom o svobode sovesti [On the Mismatch in the Regulation of Religious Tolerance by the Russian Constitution and National Legislation on Freedom of Conscience]. Vestnik Tiumenskogo gosudarstvennogo universiteta. Sotsial'no-ekonomicheskie $i$ pravovye issledovaniia,. 2019, vol. 5, no. 1, pp. 74-91.

7. Rules of Procedure concerning languages. UN GA Resolution. February 01, 1946. No. 1/2. Available at: https://undocs.org/en/A/RES/2(I) (accessed 08 August 2021).

8. Enlightenment and religious tolerance. UN GA Resolution. December 12, 2018. No. 73/128. Available it: https://undocs.org/en/A/RES/73/128 (accessed 08 August 2021).

9. Rylova A. Termin "tolerantnost"/"terpimost". Dos'e [The term "tolerance"/"patience". Dossier.]. TASS. November 16, 2015. Available at: https://tass.ru/info/2441674 (accessed 08 August 2021).

10. Simavoryan A., Ovyan V. Religioznaya tolerantnost' v sovremennom obshchestve [Religious tolerance in modern society]. 21-i Vek, 2013, no. 1 (26), pp. 82-90.

11. Sternin I.A. Tolerantnost' $i$ terpimost' [Tolerance and Patience]. December 18, 2014. Available at: http://sterninia.ru/index.php/izbrannye-publikatsii/item/188tolerantnost-i-terpimost (accessed 08 August 2021).

12. Charter of the United Nations. Available at: https://www.un.org/en/sec tions/un-charter/preamble/index.html (accessed 08 August 2021).

13. Yarkova E.N. Migraciya: tipologiya etnokul'turnoj politiki [Migration: typology of ethno-cultural policy]. Vestnik Tiumenskogo gosudarstvennogo universiteta. Sotsial'no-ekonomicheskie i pravovye issledovaniia, 2017, vol. 3, no 2. pp. 25-35.

\section{Information about the authors}

D. A. Kirillov - Candidate of Law, Associate Professor, Associate Professor of the Department of Administrative and Financial Law of the Federal State Autonomous Educational Institution of Higher Education "Tyumen State University".

E. G. Sechenova - Candidate of Philology, Vice-Rector for International Relations of the Federal State Autonomous Educational Institution of Higher Education "Tyumen State University". 